\title{
Serious Games and Gamification for Mental Health: Current Status and Promising Directions
}

\author{
Theresa M. Fleming ${ }^{1,2 *}$, Lynda Bavin ${ }^{1}$, Karolina Stasiak', Eve Hermansson-Webb', \\ Sally N. Merry', Colleen Cheek ${ }^{3}$, Mathijs Lucassen ${ }^{1,4}$, Ho Ming Lau' ${ }^{5}$, Britta Pollmuller ${ }^{6}$ \\ and Sarah Hetrick ${ }^{7}$
}

${ }^{1}$ Department of Psychological Medicine, University of Auckland, Auckland, New Zealand, ${ }^{2}$ Department of Paediatrics: Child and Youth Health, University of Auckland, Auckland, New Zealand, ' University of Tasmania Rural Clinical School, Burnie, TAS, Australia, ${ }^{4}$ Department of Health, Wellbeing and Social Care, The Open University, Milton Keynes, UK, ${ }^{5}$ Department of Psychiatry, VU University Medical Center, Amsterdam, Netherlands, ${ }^{6}$ School of Art and Design, Auckland University of Technology, Auckland, New Zealand, ${ }^{7}$ Orygen Youth Health Research Centre, Centre for Youth Mental Health, University of Melbourne, Parkville, VIC, Australia

OPEN ACCESS

Edited by:

Fotios C. Papadopoulos,

Uppsala University, Sweden

Reviewed by:

Craig Speelman,

Edith Cowan University, Australia Anna Sort,

University of Barcelona, Spain

*Correspondence:

Theresa M. Fleming

t.fleming@auckland.ac.nz

Specialty section:

This article was submitted to

Public Mental Health,

a section of the journal

Frontiers in Psychiatry

Received: 21 September 2016

Accepted: 28 December 2016

Published: 10 January 2017

Citation:

Fleming TM, Bavin L, Stasiak K, Hermansson-Webb E, Merry SN, Cheek C, Lucassen M, Lau HM, Pollmuller B and Hetrick S (2017)

Serious Games and Gamification for Mental Health: Current Status and

Promising Directions.

Front. Psychiatry 7:215.

doi: 10.3389/fpsyt.2016.00215
Computer games are ubiquitous and can be utilized for serious purposes such as health and education. "Applied games" including serious games (in brief, computerized games for serious purposes) and gamification (gaming elements used outside of games) have the potential to increase the impact of mental health internet interventions via three processes. First, by extending the reach of online programs to those who might not otherwise use them. Second, by improving engagement through both game-based and "serious" motivational dynamics. Third, by utilizing varied mechanisms for change, including therapeutic processes and gaming features. In this scoping review, we aim to advance the field by exploring the potential and opportunities available in this area. We review engagement factors which may be exploited and demonstrate that there is promising evidence of effectiveness for serious games for depression from contemporary systematic reviews. We illustrate six major categories of tested applied games for mental health (exergames, virtual reality, cognitive behavior therapy-based games, entertainment games, biofeedback, and cognitive training games) and demonstrate that it is feasible to translate traditional evidence-based interventions into computer gaming formats and to exploit features of computer games for therapeutic change. Applied games have considerable potential for increasing the impact of online interventions for mental health. However, there are few independent trials, and direct comparisons of game-based and non-game-based interventions are lacking. Further research, faster iterations, rapid testing, non-traditional collaborations, and user-centered approaches are needed to respond to diverse user needs and preferences in rapidly changing environments.

Keywords: serious gaming, games for health, gamification, computerized CBT, e-therapy, engagement

\section{INTRODUCTION}

Computer games are played by millions of adolescents (1) and adults (2) around the world, with over $40 \%$ of the United States population playing computer games for 3 or more hours per week in 2015 (2). Computer games vary enormously along dimensions such goals, interaction, and involved technologies. They include fast mini-games, as simple as lining up dots in a row, through 
to augmented reality (AR), and intricate shared worlds. Quality computer games have been shown to enhance concentration (3), improve retention of information (4), facilitate deep learning (5), and bring about behavior change (6). Over recent decades, computerized game-based approaches, both "serious games" and "gamification" have been developed for "serious" purposes: to educate, motivate, and/or persuade users, in educational, health, and other settings $(7,8)$. "Serious games" and "gamification" can be defined variously. However, both seek to employ games (or substantial game elements) in an effort to educate and change patterns of experience and/or behavior. Serious games utilize gaming as a central and primary medium (9). In contrast, gamification refers to the addition of game elements to non-game contexts (10). A gamified intervention may not operate as a full game experience but contains gaming elements, such as the scoring of points, in-game rewards, or engaging in quests.

Game-based approaches for mental health are in their infancy. However, initial studies, mainly of serious games, suggest potential benefits for psychological and behavioral changes, or symptom relief (11-17). Alongside these scientific developments, there has been significant growth in smartphone apps for mental health (18-20). Some of these use gaming or gamification, but most have not been scientifically tested (18).

To date, the potential of serious games and gamification (together "applied games" or "applied gaming") in mental health has been understudied. Where applied games have been researched, interventions are often poorly described, and diverse approaches are treated as homogeneous. In this perspective paper, we aim to advance the field by highlighting the scope of applied games for mental health. We consider the potential for applied gaming and motivational features that may be utilized. We examine evidence of effectiveness from systematic reviews and demonstrate major types of tested applied games for mental health. Finally, we highlight promising directions for development.

\section{THE POTENTIAL OF APPLIED GAMES}

Applied games are intriguing for mental health for three reasons:

First, applied gaming offers "appealing potential," as suggested by the popularity of computer games (21). Applied gaming approaches might increase the reach of mental health interventions to some who might not otherwise access help. This is important given the large numbers of people who experience mental distress and yet receive no treatment (the mental health treatment gap) (22).

Second, applied gaming has "engaging potential." Users might experience gaming approaches as enjoyable, want to "win" the game, or see how the story unfolds. Such dynamics may contribute to reducing high attrition rates in naturalistically implemented internet-based interventions $(23,24)$.

Third, applied gaming has "effectiveness potential," because it provides opportunities for both conventional and nontraditional processes for behavior change and learning. For instance, applied gaming can offer immersive experiences where a state of "flow" can be achieved, provide rich sensory environments to support learning, allow behavioral modeling and social learning, allow users to try new skills in a safe yet reactive environment, and facilitate repeated rehearsal of new behavior $(9,25-27)$.

\section{ENGAGEMENT}

Games exploit varied processes for engagement. Hamari and Tuunanen (28) carried out a meta-synthesis of 12 studies and identified key motivational orientations that support engagement. These were achievement, exploration, sociability, domination, and immersion (for examples, see Table 2). A further motivation of escape (where a user plays to escape real-life problems) has also been reported (29). A user may have several or all of these motivations for playing a game, and predominant motivations may vary across demographic groups, contexts, and types of game (28). This model could be extended to reflect the proposition that users of applied games might also have a further dimension along which their motivation varies, that of the serious purpose itself, in the present case, interest in improving mental health. For users who are motivated in this way, it may be that just a few gaming elements might enhance engagement or even that gaming elements are off-putting (30). For those less motivated to improve their mental health, stronger and more extensive gaming features may be critical.

\section{EXISTING RESEARCH: A SCOPING REVIEW}

In order to provide an overview of evidence for applied games, we carried out a review of systematic reviews. Our inclusion criteria were systematic review of serious games and/or gamified interventions for mental health (treatment or prevention), published in the peer-reviewed literature from 2010 to June 2016 (reflecting the recent development of the field), and available in English. We searched PsycINFO and Medline using the terms (systematic review) AND (mental health OR mental illness OR depression OR anxiety) AND (treatment OR prevention) AND (computer OR internet OR digital OR online) AND (game OR gaming OR gamification OR play). After duplicates were removed, a total of 18 papers were identified. A Google search and check of citations yielded no further papers for inclusion. Titles and abstracts were independently scanned by two authors (TF and LB). From these, three systematic reviews, two of which also included metaanalyses, fitted the inclusion criteria (see Table $\mathbf{1}$ ).

Each of the included papers was focused specifically on depression. Two reviews $(9,32)$ examined serious games for depression, while Li et al. (31) focused specifically on a subset of serious games, exergames. Fleming et al. (9) identified nine studies of six computerized interventions that utilized gaming as a major or primary component to treat or prevent depression. $\mathrm{Li}$ et al. (32) identified a higher number of studies, although exactly how many studies of how many interventions was not clearly reported and the search terms and inclusion criteria were not specified. As shown in Table 1, both Li et al. (32) and Fleming et al. (9) conclude that the utilization of serious games for depression is promising, but that further research is needed. Given the heterogeneity of included studies and the nature of many of these being small trials, some not randomized or controlled, stronger 
TABLE 1 | Systematic reviews of applied games for mental health.

\begin{tabular}{|c|c|c|c|c|}
\hline Reference & Scope & Inclusion criteria & Included programs (brief description) & Conclusions \\
\hline Li et al. (31) & $\begin{array}{l}\text { Systematic } \\
\text { review and } \\
\text { meta-analysis } \\
\text { of exergames } \\
\text { for depression }\end{array}$ & $\begin{array}{l}\text { Studies of exergames to treat or prevent } \\
\text { depression. Search terms and detailed } \\
\text { inclusion criteria specified. Inclusion } \\
\text { criteria include published in peer-reviewed } \\
\text { literature and reliable and valid measures } \\
\text { of depression symptoms at pre- and } \\
\text { post-intervention. Non-RCTs included }\end{array}$ & $\begin{array}{l}\text { Nine studies, eight using Wii Sports, Wii Fit or Wii } \\
\text { Fit Plus, or other commercial exergames and one } \\
\text { purpose-built rehabilitation game. Each tested for } \\
\text { impact on depression or depressive symptoms among } \\
\text { at-risk groups (mainly among elderly) }\end{array}$ & $\begin{array}{l}\text { Small, but significant } \\
\text { effect of exergames on } \\
\text { depressive symptoms. } \\
\text { Larger scale robust studies } \\
\text { needed }\end{array}$ \\
\hline $\begin{array}{l}\text { Fleming } \\
\text { et al. (9) }\end{array}$ & $\begin{array}{l}\text { Systematic } \\
\text { review of } \\
\text { serious } \\
\text { games for the } \\
\text { treatment or } \\
\text { prevention of } \\
\text { depression }\end{array}$ & $\begin{array}{l}\text { Studies of computer games/serious } \\
\text { games to treat or prevent depression. } \\
\text { Search terms and detailed inclusion } \\
\text { criteria specified. Inclusion criteria include } \\
\text { published in peer-reviewed literature and } \\
\text { reliable and valid measures of depression } \\
\text { symptoms at pre- and post-intervention. } \\
\text { Non-RCTs included }\end{array}$ & $\begin{array}{l}\text { Nine studies related to six programs: } \\
\text { Think Feel Do: } 6 \text { module computerized cognitive } \\
\text { behavior therapy (cCBT) program aimed at children/ } \\
\text { adolescents with depression or emotional distress, } \\
\text { delivered on a personal computer (PC), includes } \\
\text { game-like elements } \\
\text { SPARX: } 7 \text { module cCBT program for adolescents } \\
\text { with depression. Delivered on a PC. Utilizes a virtual } \\
\text { therapist and fantasy world setting with overarching } \\
\text { narrative and play-based learning. Rainbow SPARX: } \\
\text { modified version of SPARX for sexual minority youth } \\
\text { with depression } \\
\text { The Journey: } 7 \text { module cCBT program for adolescents } \\
\text { with depression. Delivered on a PC. Utilizes 2D fantasy } \\
\text { setting, mini-games, and puzzles with overarching } \\
\text { narrative } \\
\text { gNAT island: cognitive behavior therapy (CBT)-based } \\
\text { program delivered over } 2-4 \text { sessions with a therapist } \\
\text { Journey to the Wild Divine: a "Freeze-Framer" } \\
\text { game-based biofeedback in fantasy setting } \\
\text { ReachOutCentral: a non-modular program involving } \\
\text { interpersonal problem solving and role-playing, with the } \\
\text { story of being new in town. Utilizes principles of CBT }\end{array}$ & $\begin{array}{l}\text { Most studies reported } \\
\text { promising results, although } \\
\text { one universal program } \\
\text { (ReachOutCentral) had } \\
\text { mixed results. Interventions } \\
\text { show promise, but the } \\
\text { evidence is currently very } \\
\text { limited }\end{array}$ \\
\hline Li et al. (32) & $\begin{array}{l}\text { Systematic } \\
\text { review and } \\
\text { meta-analysis } \\
\text { of game- } \\
\text { based digital } \\
\text { interventions } \\
\text { for depression }\end{array}$ & $\begin{array}{l}\text { Studies of game-based digital applications } \\
\text { for depression. Search terms not specified } \\
\text { and inclusion criteria are not detailed; } \\
\text { however, they must include reliable and } \\
\text { valid measures of depression symptoms. } \\
\text { Surveys, non-RCTs, and single case } \\
\text { studies were included }\end{array}$ & $\begin{array}{l}\text { Identified } 19 \text { studies including: } \\
\text { Exercise games for depression among older adults, } \\
\text { using Nintendo Wii [as included in Ref. (31)] } \\
\text { SPARX, ReachOutCentral, and Journey to the Wild } \\
\text { Divine [as included in Ref. (9)] } \\
\text { Virtual reality interventions for PTSD, phobia, or depression } \\
\text { Entertainment games tested for impact on psychological } \\
\text { symptoms } \\
\text { Programs that are not described as games or gamified } \\
\text { by the original authors such as Beating the Blues }\end{array}$ & $\begin{array}{l}\text { Findings support } \\
\text { effectiveness, but further } \\
\text { research is needed }\end{array}$ \\
\hline
\end{tabular}

conclusions would be premature. In the more narrowly focused review (31), only three Randomised Controlled Trials (RCTs) were identified; however, the authors reported a significant effect of exergames on depressive symptoms. As noted in each review, there was a lack of direct comparison of game-based to nongaming interventions, and most studies were not independent of the developers. The research is at an early stage.

\section{TYPES OF APPLIED GAMES}

The three systematic reviews included six main types of applied games. Each of these categories is outlined below. An example of each, and potential mechanisms for therapeutic change and engagement, is given in Table 2.

\section{Exergames}

Exergames are sport or movement-based games. Nine of the included studies (across the three reviews) tested the use of exergames for depressive symptoms, primarily among older adults (31). Eight studies used "repurposed games," games developed for entertainment or commercial purposes and now tested for mental health. One was purpose-built. Li et al. (31) reported a significant effect of exergames on depressive symptoms, with this being higher among more playful games, over those that included less game elements. However, these results should be interpreted with caution, given that only three of the studies were RCTs, and the sample sizes were small.

\section{Virtual Reality Games}

Virtual Reality (VR) and Augmented Reality (AR) can offer immersive interactivity in a virtual or augmented world, with visual, audio, and sometimes other sensory stimuli, to increase user engagement and possibly therapeutic impact $(38,39)$. Li et al. (32) identified six studies of VR gaming interventions. They reported that these had positive results. However, only 2 had over 10 participants, and most of the original papers provide 
TABLE 2 | Examples of major types of tested applied games for mental health.

\begin{tabular}{|c|c|c|c|c|c|c|c|c|}
\hline \multirow{3}{*}{$\begin{array}{l}\text { Types of } \\
\text { game }\end{array}$} & \multirow[t]{3}{*}{ Example } & \multirow{3}{*}{$\begin{array}{l}\text { Main } \\
\text { therapeutic } \\
\text { modality }\end{array}$} & \multicolumn{6}{|c|}{ Increasing engagement } \\
\hline & & & \multicolumn{5}{|c|}{$\begin{array}{l}\text { Examples of game-focused engagement features } \\
\text { (facilitating engagement via user game-related motivations) }\end{array}$} & \multirow{2}{*}{$\begin{array}{l}\text { Serious } \\
\text { purpose } \\
\text { engagement } \\
\text { features }\end{array}$} \\
\hline & & & Achievement & Exploration & Sociability & Domination & Immersion & \\
\hline Exergames & $\begin{array}{l}\text { Nintendo } \\
\text { Wii Sports } \\
\text { (33) }\end{array}$ & $\begin{array}{l}\text { Exercise, } \\
\text { perhaps } \\
\text { behavioral } \\
\text { activation, social } \\
\text { activity }\end{array}$ & $\begin{array}{l}\text { Improve performance } \\
\text { on sports games to } \\
\text { increase the avatar's } \\
\text { skill level and to } \\
\text { turn "pro." Features } \\
\text { fitness test }\end{array}$ & $\begin{array}{l}\text { Explore } \\
\text { different virtual } \\
\text { sports settings }\end{array}$ & $\begin{array}{l}\text { Can play with } \\
\text { others }\end{array}$ & $\begin{array}{l}\text { Compete } \\
\text { against } \\
\text { others to win } \\
\text { tournaments }\end{array}$ & $\begin{array}{l}\text { Requires } \\
\text { real-time } \\
\text { movement to } \\
\text { play the game. } \\
\text { Real-time } \\
\text { performance } \\
\text { feedback }\end{array}$ & Not described \\
\hline Virtual reality & $\begin{array}{l}\text { Virtual Iraq } \\
\text { (34) }\end{array}$ & $\begin{array}{l}\text { Exposure } \\
\text { therapy }\end{array}$ & $\begin{array}{l}\text { Habituate to } \\
\text { progressively more } \\
\text { provocative elements } \\
\text { to progress through } \\
\text { the recreated virtual } \\
\text { environment }\end{array}$ & $\begin{array}{l}\text { User navigates } \\
\text { through virtual } \\
\text { 3D simulation } \\
\text { of combat } \\
\text { environments }\end{array}$ & N/A & $\begin{array}{l}\text { Confront } \\
\text { provocative } \\
\text { elements in } \\
\text { the traumatic } \\
\text { scenario to } \\
\text { gain control } \\
\text { over emotional } \\
\text { responses }\end{array}$ & $\begin{array}{l}\text { Immersive } \\
\text { sensory 3D } \\
\text { experience } \\
\text { (rich 3D } \\
\text { graphics } \\
\text { and audio, } \\
\text { olfactory, and } \\
\text { vibrotactile } \\
\text { stimuli) }\end{array}$ & $\begin{array}{l}\text { Clinician } \\
\text { provides } \\
\text { rationale }\end{array}$ \\
\hline $\begin{array}{l}\text { Cognitive } \\
\text { behavior } \\
\text { therapy } \\
\text { (CBT)-based } \\
\text { serious } \\
\text { games }\end{array}$ & $\operatorname{SPARX}(16)$ & CBT & $\begin{array}{l}\text { Complete quizzes, } \\
\text { shoot gNats (gloomy } \\
\text { negative automatic } \\
\text { thoughts), and find } \\
\text { gems to ultimately } \\
\text { restore balance to } \\
\text { the virtual world }\end{array}$ & $\begin{array}{l}\text { Explore virtual } \\
\text { world }\end{array}$ & $\begin{array}{l}\text { Player } \\
\text { interacts with } \\
\text { virtual guide/ } \\
\text { therapist and } \\
\text { other in-game } \\
\text { characters }\end{array}$ & Defeat gNats & $\begin{array}{l}\text { Interactive } \\
\text { narrative ("a } \\
\text { hero to save } \\
\text { the world"). } \\
\text { Rich graphics }\end{array}$ & $\begin{array}{l}\text { Virtual guide } \\
\text { explains how } \\
\text { the game is } \\
\text { helpful for } \\
\text { difficulties } \\
\text { and can be } \\
\text { applied in } \\
\text { real-life }\end{array}$ \\
\hline $\begin{array}{l}\text { CBT-based } \\
\text { gamification }\end{array}$ & $\begin{array}{l}\text { SuperBetter } \\
\text { (35) }\end{array}$ & $\begin{array}{l}\text { CBT and positive } \\
\text { psychology }\end{array}$ & $\begin{array}{l}\text { Gain points and } \\
\text { "level-up." Complete } \\
\text { quests and power- } \\
\text { ups. Defeat "bad } \\
\text { guys" }\end{array}$ & $\mathrm{N} / \mathrm{A}$ & $\begin{array}{l}\text { Facebook } \\
\text { integration and } \\
\text { online forums. } \\
\text { Encourages } \\
\text { connections } \\
\text { with allies }\end{array}$ & $\begin{array}{l}\text { Defeat "bad } \\
\text { guys" (by } \\
\text { overcoming } \\
\text { specific } \\
\text { obstacles) }\end{array}$ & $\begin{array}{l}\text { Fun bite-sized } \\
\text { activities. Can } \\
\text { create own } \\
\text { power-ups } \\
\text { and quests }\end{array}$ & $\begin{array}{l}\text { Program } \\
\text { explicitly } \\
\text { provides } \\
\text { rationale } \\
\text { for why } \\
\text { intervention } \\
\text { helps with } \\
\text { resilience and } \\
\text { mood }\end{array}$ \\
\hline Biofeedback & $\begin{array}{l}\text { Journey to } \\
\text { the Wild } \\
\text { Divine (36) }\end{array}$ & $\begin{array}{l}\text { Psychoeducation } \\
\text { and relaxation- } \\
\text { based exercises } \\
\text { paired with } \\
\text { biofeedback }\end{array}$ & $\begin{array}{l}\text { See progress over } \\
\text { time via high-score } \\
\text { tracking. Control } \\
\text { physiology in order to } \\
\text { successfully perform } \\
\text { virtual activities, such } \\
\text { as building a bridge } \\
\text { or shooting a bow } \\
\text { and arrow }\end{array}$ & $\begin{array}{l}\text { Explore serene } \\
\text { virtual worlds/ } \\
\text { environments }\end{array}$ & $\begin{array}{l}\text { Encounter } \\
\text { various guides } \\
\text { and mentors } \\
\text { in the virtual } \\
\text { environment }\end{array}$ & $\mathrm{N} / \mathrm{A}$ & $\begin{array}{l}\text { Controlling } \\
\text { physiology to } \\
\text { play the game. } \\
\text { Rich graphics } \\
\text { and immersive } \\
\text { sound }\end{array}$ & $\begin{array}{l}\text { In-game } \\
\text { explanation } \\
\text { about how } \\
\text { program } \\
\text { works to } \\
\text { prevent or } \\
\text { relieve stress } \\
\text { and enhance } \\
\text { well-being }\end{array}$ \\
\hline $\begin{array}{l}\text { Entertainment } \\
\text { computer } \\
\text { games for } \\
\text { mental health }\end{array}$ & Tetris (37) & $\begin{array}{l}\text { Redirection } \\
\text { of cognitive } \\
\text { resources }\end{array}$ & $\begin{array}{l}\text { Clear lines to } \\
\text { successfully level-up }\end{array}$ & $\mathrm{N} / \mathrm{A}$ & $\begin{array}{l}\text { Can play } \\
\text { against others } \\
\text { and watch } \\
\text { tournaments. } \\
\text { Online forums }\end{array}$ & $\begin{array}{l}\text { Defeat other } \\
\text { players in } \\
\text { multi-level } \\
\text { modes and } \\
\text { competitions. } \\
\text { Leaderboards }\end{array}$ & $\begin{array}{l}\text { Playing against } \\
\text { the clock (time } \\
\text { pressure) }\end{array}$ & $\begin{array}{l}\text { Therapist } \\
\text { may provide } \\
\text { explanation }\end{array}$ \\
\hline
\end{tabular}

little detail regarding the game. Hence an alternative example, that of Virtual Iraq for PTSD (34) is given in Table 2. Promising findings from VR interventions, including non-game-based VR interventions (40) along with the popularity of commercial AR games, suggest promise in this area.

\section{Cognitive Behavior Therapy (CBT)-Based Serious Games and Gamification}

Five of the interventions identified in the systematic reviews were multilevel CBT-based programs, often utilizing a fantasy environment, and designed to be completed at a rate of 
approximately one level per week on a personal computer. Each of these programs was aimed at children or young people. Each reported positive or promising results, except for ReachOutCentral, which had mixed findings and has since been retired. Of these, SPARX is described in the greatest depth and is outlined in Table 2.

A further example, SuperBetter, has been tested since the publication of the systematic reviews; however, it is included here (Table 2), as it illustrates new opportunities for applied games. SuperBetter is a positive psychology program in which players earn points and "level-up," as they progress through activities. Rather than being a narrative-based serious game, SuperBetter offers a more gamified approach, with scoring and rewards. In another point of difference, SuperBetter allows "snacktivity," frequent, brief activities that can be done a few minutes at a time, every day or more often (therefore like "snacking" behavior). This pattern of use is common in contemporary online apps but is not common in tested online mental health tools to date, many of which follow traditional clinical therapeutic models (e.g., weekly sessions of 30 minutes or more). In a recent RCT, participants who were asked to play SuperBetter for 10 minutes daily over 30 days experienced significantly greater reductions in depressive symptoms and anxiety compared to a waitlist control group; however, attrition was high (35).

\section{Entertainment Computer Games}

This category of interventions is quite different from those that translate an evidence-based mental health therapy (such as CBT or exposure therapy) into a game format. In this grouping, entertainment video games were tested for effects on mood. Several studies of this nature were included in Li et al. (32). In the first of these, students were given a "frustrating task" and then 45 minutes of violent video game play or a control condition. Those playing the violent game reported lower symptoms of depression immediately following the intervention in one study (41). However, in a second study, no effect for depression was reported (42). In a further study, Rossoniello et al. (43) reported subjects had improved mood immediately following playing a casual video game Bejeweled II. These entertainment games were proposed to affect mood via emotional regulation, stress release, or social support pathways.

A different form of using commercial games for mental health is the use of the puzzle game Tetris for therapeutic purposes. In Tetris, players strategically move, rotate, and drop "Tertriminos" to complete horizontal lines. Engaging in this visuospatial cognitive activity when memories are activated is proposed to help impede traumatic flashbacks in PTSD by interfering with memory consolidation (37). Preliminary findings have also shown promise for using Tetris to reduce cravings (44).

\section{Biofeedback-Based Games}

The included reviews described two biofeedback-based games: the Journey to the Wild Divine and Freeze-Framer 2.0. In each of these, users rehearse relaxation skills while receiving visual feedback on physiological indicators (measured using a sensor attached to the ear lobe or the fingertips). In a small trial, youth receiving the intervention had significantly lower post-intervention levels of depression and anxiety compared to those in a waitlist control group (36).

\section{Cognitive Training Games}

The reviews included one study using cognitive training games. Alvarez et al. (45) tested number and letter sequence training games to reduce cognitive impairment in 31 depressed students. In this study, the game had positive results on cognitive impairment, but direct effects on mood were not tested.

\section{FUTURE DIRECTIONS}

It is demonstrably feasible to translate traditional evidence-based interventions, such as CBT and exposure therapies, to computer gaming formats. Included interventions have shown that it is also possible to exploit features of computer games for therapeutic change using mechanisms that are not traditionally salient in psychological therapies, such as in the example of Tetris for PTSD. Further, the potential for positive mental health outcomes from casual play of entertainment games is worthy of exploration, as this might offer opportunities to reach large numbers of people. Each of these approaches appears to be promising. However, this evidence is at an early stage, and independent, larger robust studies are needed. Further, there is a lack of data regarding whether gaming-based approaches might be more appealing than non-gaming mental health interventions for users with different motivations, including both those who do and those who do not want to access help for distress. This is a question for future research. Similarly, findings from trials and user reviews of some commercially available programs suggest that applied gaming approaches can be engaging; however, many analyses do not report engagement or ongoing use. The assertion that quality gaming dynamics will increase engagement, at least for some users, should also be tested in future research.

We have highlighted that applied gaming interventions vary widely, in terms of types of games and in terms of features that might be appealing and motivating. It would be valuable to explore popular engaging game types for target groups and compare features in those games with those used in games for mental health. For example, highly accessed games currently include smart phone-based mini-games, massive multiplayer games where millions of players interact, games that allow usergenerated content, and games that are linked to popular social media platforms $(2,46,47)$. These approaches did not feature strongly in the included interventions.

Despite the potential for applied gaming, there are challenges in proposing such approaches, including costs, speed of implementation, issues of face validity, and user preferences. Many gamers will be familiar with commercially produced games, which often involve development budgets in the tens of millions of dollars $(48,49)$. Even simple mini-games undergo rapid advances, with new versions regularly released. Funding limitations make it challenging to develop and maintain comparable scientific initiatives.

Speed of implementation is also critical (49). Traditional scientific methods of sequential development, piloting, refinement, testing in a RCT, followed by publication, and independent 
replication, prior to real-world implementation, will ensure that evidence-based applied gaming lags behind the rapidly shifting commercial hardware and software environments. Newer methodological approaches are available (24).

Rather different challenges include those of face validity and diverse user motivations. People often do not seek help for mental health issues until these are relatively serious (22), in which case a game may be perceived as trivializing or inappropriate (Fleming et al., manuscript in preparation). Conversely, those who do not want therapeutic help might be irked that their game has a mental health agenda as suggested by the gamergate phenomena (50). These factors should be investigated in future research. The diversity of gaming approaches and user motivations also pose challenges. Not all games are successful. Quality game development requires specialist skills, and meeting user preferences may necessitate the creation of a range of interventions.

We have previously proposed four key ways of maximizing the impact of E-therapies and serious games in mental health. Utilizing this framework, as identified by the Collaboration on Maximizing the impact of E-therapy and Serious Gaming (COMETS) (24), we believe that to achieve significant mental health benefits, the field requires:

- User-centered approaches. This necessitates exploring the motivations and preferences of user groups for addressing their mental health needs. The field of game development has illustrated that this is unlikely to be through one approach or single engagement factor for all users.

- Engaging, as well as effective interventions. Even very effective interventions will have limited population impact if they are not engaging. Studies should explore and report engagement as well as effectiveness and provide sufficient detail regarding dynamics used, to allow others to build on their work.

- Intersectorial and international collaborations. The skills required to develop engaging and effective games with high

\section{REFERENCES}

1. Brooks FM, Chester KL, Smeeton NC, Spencer NH. Video gaming in adolescence: factors associated with leisure time use. J Youth Stud (2016) 19(1):36-54. doi:10.1080/13676261.2015.1048200

2. Entertainment Software Association. Essential Facts about the Computer and Video Game Industry. (2015). Available from: http://www.theesa.com/ wp-content/uploads/2015/04/ESA-Essential-Facts-2015.pdf

3. Connolly TM, Boyle EA, MacArthur E, Hainey T, Boyle JM. A systematic literature review of empirical evidence on computer games and serious games. Comput Educ (2012) 59(2):661-86. doi:10.1016/j.compedu.2012.03.004

4. Andrews A. Serious games for psychological health education. In: Shumaker R, editor. Virtual and Mixed Reality - Systems and Applications. Berlin, Heidelberg: Springer (2011). p. 3-10.

5. Dondlinger MJ. Educational video game design: a review of the literature. J Appl Educ Technol (2007) 4(1):21-31.

6. Read JL, Shortell SM. Interactive games to promote behavior change in prevention and treatment. J Am Med Assoc (2011) 305(16):1704-5. doi:10.1001/ jama.2011.408

7. Burke JW, McNeill MDJ, Charles DK, Morrow PJ, Crosbie JH, McDonough SM. Optimising engagement for stroke rehabilitation using serious games. Vis Comput (2009) 25(12):1085-99. doi:10.1007/s00371-009-0387-4

8. Chatham RE. Games for training. Commun ACM (2007) 50(7):36-43. doi:10.1145/1272516.1272537 uptake are diverse and go beyond many science or clinically focused teams. Further, the costs of developing interventions may be more easily borne across sectors and jurisdictions.

- Rapid testing and implementation. User expectations in technology-driven approaches and gaming evolve rapidly. Innovative, rapid research designs and planning for implementation are needed to ensure that interventions are still appealing when they are ready for implementation.

\section{CONCLUSION}

In this perspective paper, we have illustrated the potential of serious games and gamification for mental health and highlighted that there is serious work still to be done. The field is ready for further development, as the feasibility and range of possible approaches has been shown, and as there is an urgent need for engaging, appealing effective mental health interventions which reach large numbers of people. Future research should include independent trials and direct comparisons of game-based and non-game-based options for varied user groups.

\section{AUTHOR CONTRIBUTIONS}

TF drafted the paper, coordinated the input from other authors, and was responsible for the full submission. LB assisted with drafting and completing all aspects of the paper. All other authors contributed substantially to the draft and approved final submission.

\section{FUNDING}

No specific funds were received for the preparation of this paper. All authors are staff or $\mathrm{PhD}$ candidates, and the manuscript was prepared as part of these roles.

9. Fleming T, Cheek C, Merry S, Thabrew H, Bridgman H, Stasiak K, et al Serious games for the treatment or prevention of depression: a systematic review. Revista de Psicopatología y Psicología Clínica (2014) 19(3):227-42. doi:10.5944/rppc.vol.19.num.3.2014.13904

10. Deterding S, Dixon D, Khaled R, Nacke L. From game design elements to gamefulness: defining gamification. Proceedings of the 15th International Academic MindTrek Conference: Envisioning Future Media Environments. Tampere: ACM (2011). p. 9-15.

11. Anguera JA, Boccanfuso J, Rintoul JL, Al-Hashimi O, Faraji F, Janowich J, et al. Video game training enhances cognitive control in older adults. Nature (2013) 501(7465):97-101. doi:10.1038/nature12486

12. Fleming T, Dixon R, Frampton C, Merry S. A pragmatic randomized controlled trial of computerized CBT (SPARX) for symptoms of depression among adolescents excluded from mainstream education. Behav Cogn Psychother (2012) 40(05):529-41. doi:10.1017/S1352465811000695

13. Khazaal Y, Chatton A, Prezzemolo R, Zebouni F, Edel Y, Jacquet J, et al. Impact of a board-game approach on current smokers: a randomized controlled trial. Subst Abuse Treat Prev Policy (2013) 8(1):1. doi:10.1186/1747-597X-8-3

14. Khazaal Y, Chatton A, Dieben K, Huguelet P, Boucherie M, Monney G, et al. Reducing delusional conviction through a cognitive-based group training game: a multicentre randomized controlled trial. Front Psychiatry (2015) 6:66. doi:10.3389/fpsyt.2015.00066

15. Leutwyler H, Hubbard E, Cooper B, Dowling G. The impact of a videogamebased pilot physical activity program in older adults with schizophrenia 
on subjectively and objectively measured physical activity. Front Psychiatry (2015) 6:180. doi:10.3389/fpsyt.2015.00180

16. Merry SN, Stasiak K, Shepherd M, Frampton C, Fleming T, Lucassen MF. The effectiveness of SPARX, a computerised self help intervention for adolescents seeking help for depression: randomised controlled non-inferiority trial. $B M J$ (2012) 344:e2598. doi:10.1136/bmj.e2598

17. Tárrega S, Castro-Carreras L, Fernández-Aranda F, Granero R, GinerBartolomé C, Aymamí N, et al. A serious videogame as an additional therapy tool for training emotional regulation and impulsivity control in severe gambling disorder. Front Psychol (2015) 6:1721. doi:10.3389/fpsyg.2015.01721

18. Bakker D, Kazantzis N, Rickwood D, Rickard N. Mental health smartphone apps: review and evidence-based recommendations for future developments. JMIR Ment Health (2016) 3(1):e7. doi:10.2196/mental.4984

19. Martínez-Pérez B, De La Torre-Díez I, López-Coronado M. Mobile health applications for the most prevalent conditions by the World Health Organization: review and analysis. JMed Internet Res (2013) 15(6):e120. doi:10.2196/jmir.2600

20. Miloff A, Marklund A, Carlbring P. The challenger app for social anxiety disorder: new advances in mobile psychological treatment. Internet Interv (2015) 2(4):382-91. doi:10.1016/j.invent.2015.08.001

21. Marchand A, Hennig-Thurau T. Value creation in the video game industry: industry economics, consumer benefits, and research opportunities. J Interact Mark (2013) 27:141-57. doi:10.1016/j.intmar.2013.05.001

22. Andrade LH, Alonso J, Mneimneh Z, Wells JE, Al-Hamzawi A, Borges G, et al. Barriers to mental health treatment: results from the WHO World Mental Health (WMH) Surveys. Psychol Med (2014) 44(6):1303-17. doi:10.1017/ S0033291713001943

23. Batterham PJ, Neil AL, Bennett K, Griffiths KM, Christensen H. Predictors of adherence among community users of a cognitive behavior therapy website. Patient Prefer Adherence (2008) 2:97-105.

24. Fleming TM, de Beurs D, Khazaal Y, Gaggioli A, Riva G, Botella C, et al. Maximizing the impact of E-therapy and serious gaming: time for a paradigm shift. Front Psychiatry (2016) 7:65. doi:10.3389/fpsyt.2016.00065

25. Eyal N. Hooked: How to build Habit-Forming Products. Canada: Penguin (2014).

26. Cheek C, Fleming T, Lucassen MF, Bridgman H, Stasiak K, Shepherd M, et al. Integrating health behavior theory and design elements in serious games. JMIR Ment Health (2015) 2(2):doi:10.2196/mental.4133

27. Oulasvirta A, Rattenbury T, Ma L, Raita E. Habits make smartphone use more pervasive. Pers Ubiquit Comput (2012) 16(1):105-14. doi:10.1007/ s00779-011-0412-2

28. Hamari J, Tuunanen J. Player types: a meta-synthesis. Trans Digit Games Res Assoc (2014) 1(2):29-53.

29. Billieux J, Van der Linden M, Achab S, Khazaal Y, Paraskevopoulos L, Zullino D, et al. Why do you play World of Warcraft? An in-depth exploration of self-reported motivations to play online and in-game behaviours in the virtual world of Azeroth. Comput Human Behav (2013) 29(1):103-9. doi:10.1016/j. chb.2012.07.021

30. Khazaal Y, Fernandez S, Cochand S, Reboh I, Zullino D. Quality of web-based information on social phobia: a cross-sectional study. Depress Anxiety (2008) 25(5):461-5. doi:10.1002/da.20381

31. Li J, Theng YL, Foo S. Effect of Exergames on depression: a systematic review and meta-analysis. Cyberpsychol Behav Soc Netw (2016) 19(1):34-42. doi:10.1089/cyber.2015.0366

32. Li J, Theng YL, Foo S. Game-based digital interventions for depression therapy: a systematic review and meta-analysis. Cyberpsychol Behav Soc Netw (2014) 17(8):519-27. doi:10.1089/cyber.2013.0481

33. Rosenberg D, Depp CA, Vahia IV, Reichstadt J, Palmer BW, Kerr J, et al. Exergames for subsyndromal depression in older adults: a pilot study of a novel intervention. Am J Geriatr Psychiatry (2010) 18(3):221-6. doi:10.1097/ JGP.0b013e3181c534b5

34. Rizzo A, Difede J, Rothbaum BO, Daughtry JM, Reger G. Virtual reality as a tool for delivering PTSD exposure therapy. In: Safir MP, Wallach HS, Rizzo A, editors. Post-Traumatic Stress Disorder: Future Directions in Prevention, Diagnosis, and Treatment. New York: Springer (2013).
35. Roepke A, Jaffee S, Riffle O, McGonigal J, Broome R, Bez M. Randomized controlled trial of SuperBetter, a smartphone-based/Internet-based self-help tool to reduce depressive symptoms. Games Health $J$ (2015) 4(3):235-46. doi:10.1089/g4h.2014.0046

36. Knox M, Lentini J, Cummings TS, McGrady A, Whearty K, Sancrant L. Game-based biofeedback for paediatric anxiety and depression. Men Health Fam Med (2011) 8(3):195.

37. Holmes EA, James EL, Coode-Bate T, Deeprose C. Can playing the computer game "Tetris" reduce the build-up of flashbacks for trauma? A proposal from cognitive science. PLoS One (2009) 4(1):e4153. doi:10.1371/journal. pone. 0004153

38. Gutiérrez-Maldonado J, Wiederhold BK, Riva G. Future directions: how virtual reality can further improve the assessment and treatment of eating disorders and obesity. Cyberpsychol Behav Soc Netw (2016) 19(2):148-53. doi:10.1089/cyber.2015.0412

39. Laforest M, Bouchard S, Crétu AM, Mesly OD. Inducing an anxiety response using a contaminated virtual environment: validation of a therapeutic tool for obsessive-compulsive disorder. Front ICT (2016) 3:18. doi:10.3389/ fict.2016.00018

40. Riva G, Baños RM, Botella C, Mantovani F, Gaggioli A. Transforming experience: the potential of augmented reality and virtual reality for enhancing personal and Clinical change. Front Psychiatry (2016) 7:164. doi:10.3389/ fpsyt.2016.00164

41. Ferguson CJ, Rueda SM. The Hitman Study. Eur Psychol (2010) 15(2):99-108. doi:10.1027/1016-9040/a000010

42. Valadez JJ, Ferguson CJ. Just a game after all: violent video game exposure and time spent playing effects on hostile feelings, depression, and visuospatial cognition. Comput Human Behav (2012) 28(2):608-16. doi:10.1016/j. chb.2011.11.006

43. Rossoniello CV, O’Brien K, Parks JM. The effectiveness of casual video games in improving mood and decreasing stress. J Cyber Ther Rehabil (2009) 2(1):53-66.

44. Skorka-Brown J, Andrade J, Whalley B, May J. Playing Tetris decreases drug and other cravings in real world settings. Addict Behav (2015) 51:165-70. doi:10.1016/j.addbeh.2015.07.020

45. Alvarez L, Sotres J, León S, Estrella J, Sosa J. Computer program in the treatment for major depression and cognitive impairment in university students. Comput Human Behav (2008) 24:3. doi:10.1016/j.chb.2007.02.013

46. Rice SM, Goodall J, Hetrick SE, Parker AG, Gilbertson T, Amminger GP, et al. Online and social networking interventions for the treatment of depression in young people: a systematic review. J Med Internet Res (2014) 16(9):e206. doi:10.2196/jmir.3304

47. Robinson J, Cox G, Bailey E, Hetrick S, Rodrigues M, Fisher S, et al. Social media and suicide prevention: a systematic review. Early Interv Psychiatry (2015) 10(2):103-21. doi:10.1111/eip.12229

48. Baranowski T, Buday R, Thompson DI, Baranowski J. Playing for real: video games and stories for health-related behavior change. Am J Prev Med (2008) 34(1):74-82. doi:10.1016/j.amepre.2007.09.027

49. Zyda M. From visual simulation to virtual reality to games. Computer (2005) 38(9):25-32. doi:10.1109/MC.2005.297

50. Wikipedia. Gamergate Controversy. Wikimedia Foundation (2016). Available from: https://en.wikipedia.org/wiki/Gamergate_controversy

Conflict of Interest Statement: The intellectual property for SPARX is held by UniServices at the University of Auckland. Any proceeds from licensing or selling SPARX outside of New Zealand will be shared in part with UniServices and SM, KS, TF, M. Shepherd, and ML.

Copyright (c) 2017 Fleming, Bavin, Stasiak, Hermansson-Webb, Merry, Cheek, Lucassen, Lau, Pollmuller and Hetrick. This is an open-access article distributed under the terms of the Creative Commons Attribution License (CC BY). The use, distribution or reproduction in other forums is permitted, provided the original author(s) or licensor are credited and that the original publication in this journal is cited, in accordance with accepted academic practice. No use, distribution or reproduction is permitted which does not comply with these terms. 